\title{
IDEOLOGIA DE GÊNERO: POSSIBILIDADES DE ANÁLISE A PARTIR DE UMA REVISÃO DE LITERATURA
}

\author{
“Gender Ideology": Possibilities of Analysis from a Literature Review
}

Carlos Eduardo Barzotto ${ }^{1}$

\begin{abstract}
Resumo: Este artigo tem como objetivo mapear o debate acadêmico acerca do sintagma "ideologia de gênero", enfatizando as relações de poder que ele estabelece na sociedade, a partir de uma revisão de literatura sobre o assunto. Tal necessidade se expressa pela enorme profusão de sentidos atribuídos à "ideologia de gênero" na arena pública, sobretudo nos debates educacionais. A partir da discussão teórico-metodológica, foram selecionados, lidos e sistematizados setenta e quatro materiais acadêmicos que tematizam a questão. Por conta da sistematização realizada, argumenta-se aqui que os estudos brasileiros sobre "ideologia de gênero" têm uma maior proximidade com os estudos educacionais quando comparados às outras produções localizadas. Além disso, também se argumenta nesse artigo que o movimento antigênero que se expressa através da difusão do sintagma "ideologia de gênero" tem buscado disputar sentidos e significados sobre os conceitos de "gênero" e "sexualidade" a partir da construção de uma retórica pretensamente científica que une oportunamente Biologia e do Direito. Tal retórica é considerada aqui como um dos muitos passos responsáveis pela deslegitimação dos estudos de gênero e sexualidade na arena pública, bem como pelo ataque à escola pública e à liberdade de ensino.
\end{abstract}

Palavras-chave: Ideologia de Gênero. Estudos de Gênero. Revisão de Literatura.

\begin{abstract}
This article has as its objective to map the academic debate about the expression "gender ideology", emphasizing the power relations that it establishes in society, from a literature review on the matter. Such necessity is expressed by the huge profusion of senses attributed to "gender ideology" in the public arena, mainly in the educational debates. From theoretical-methodological discussion, seventy-four academic materials that themed the subject were selected, read and systematized. Because of the systematization done, it is argued here that the Brazilian studies about "gender ideology" have a broader proximity with educational studies when compared to the other located productions. Moreover, it is also argued in this article that the antigender movement that expresses itself through the diffusion of the expression "gender ideology" has aimed to dispute senses and meanings about the concepts of "gender" and "sexuality" from a construction of a allegedly scientific rhetoric that binds opportunely Biology and Law. Such rhetoric is considered here as one of the many steps responsible for the delegitimation of gender and sexuality studies in the public arena, as well as for the attack against the public school and the teaching liberty.
\end{abstract}

Keywords: Gender Ideology. Gender Studies. Literature Review

\footnotetext{
${ }^{1}$ Mestre em Educação pela Universidade Federal do Rio Grande do Sul, licenciado e bacharelando em História pela mesma instituição. Atualmente, atua como professor de História junto à Secretaria de Educação de Guaíba/RS. Orcid: https://orcid.org/0000-0003-3355-0087. Endereço de contato: cebarzotto@gmail.com.
} 


\title{
1 Nuvens carregadas no horizonte: a introdução
}

Em setembro de 2018, durante as eleições presidenciais brasileiras, um usuário do Facebook compartilhou, na rede social, um vídeo em que segurava uma mamadeira que tinha, no lugar do bico, uma figura em formato de pênis. Segundo o autor da postagem, esse objeto faz parte do kit anti-homofobia, que teria sido criado pelo então candidato à presidência da república do Partido dos Trabalhadores (PT), Fernando Haddad, e seria distribuído "em creche, para seu filho, com a desculpa de combater a homofobia" (ESTADÃO VERIFICA, 2018). Apesar de tal publicação ter sido veiculada como notícia falsa pelas mídias tradicionais e alternativas, o vídeo alcançou cerca 2,4 milhões de visualizações entre os dias 25 e 27 de setembro, de acordo com o jornal Estadão.

No mês seguinte, em entrevista cedida ao Programa Jornal Nacional, o então candidato à presidência da República pelo Partido Social Liberal (PSL), Jair Messias Bolsonaro, exibiu ao vivo o livro "Aparelho Sexual \& Cia", que ele afirmava estar sendo enviado para as escolas brasileiras, com o objetivo de ensinar a chamada "ideologia de gênero". Essa ação foi desmentida, assim como a anterior, por diversos canais midiáticos, como por uma reportagem do jornal El País ${ }^{2}$.

Enquanto pesquisadores do campo educacional e dos estudos de gênero e sexualidade, cabe questionarmos, a partir das situações acima, quais são as concepções sobre escola, gênero e sexualidade que permeiam esses discursos? Quais são os interesses desses sujeitos ao enunciá-los? De que modo discursos como esses estão sendo aceitos e/ou reproduzidos na arena pública e quais os impactos disso para a nossa área de atuação e pesquisa?

De acordo com Marlucy Paraíso (2018, p. 23), há um forte movimento conservador no Brasil, que visa "[...] impedir que a diferença se prolifere e para fazer com que gênero e sexualidade sejam considerados temas não escolares". Para a autora, há uma tormenta forte e inesperada no cenário público, que

\begin{abstract}
trata-se de uma avalanche de ideias reacionárias que busca inundar a todos e a todas com moralismos, divisões naturalizadas, identidades fixas, generificações hierárquicas, silêncios interessados, ódios destruidores, omissões desastrosas, retrocessos inaceitáveis. (PARAÍSO, 2018, p. 25).
\end{abstract}

Apropriando-me da alegoria de Paraíso, creio que, como é característico da expectativa pela tormenta, há também preparo. Se por um lado o slogan ou sintagma "ideologia de gênero" traz consigo ventos, chuvas, relâmpagos e desestabilidade para os estudos e para o ensino de gênero e sexualidade na arena pública, por outro lado deve haver o preparo para enfrentar essa tormenta. Para isso, é necessário reconhecer o movimento (ultra)conservador e antigênero que impulsiona tal sintagma no país.

Tal movimento é entendido aqui como articulado em torno do slogan "ideologia de gênero" como um movimento antigênero, pois essa categoria é composta, conforme argumentam David Paternotte e Roman Kuhar (2017), por uma ampla pluralidade de grupos, sujeitos e ações que formam ou são afetados por discursos ultraconservadores e populistas no que diz respeito à moral. Nesse sentido, os países afetados por esses movimentos “[...] estão enfrentando formas específicas de mobilização que não deveriam ser entendidas como meras reiterações do passado, mas sim como novas formas de mobilização contra a igualdade de gênero e de sexualidade" (PATERNOTTE, KUHAR, 2017, p. 253 - tradução minha). 
Entende-se, ademais, que tal movimento é de origem vaticana (JUNQUEIRA, 2017) - apesar de não ser seu monopólio - e visa recristianizar sociedades laicas ou em processo de laicização.

A partir desse contexto, este artigo tem como objetivo mapear o debate acadêmico sobre o sintagma "ideologia de gênero", enfatizando as relações de poder que ele estabelece na sociedade, a partir de uma revisão de literatura do assunto. Para tanto, utilizo de referenciais advindos de estudos bibliométricos e de estado da arte de modo a localizar, mapear e reconhecer o que se fala sobre o movimento deflagrado em torno da expressão "ideologia de gênero". Com tal esforço, este artigo contribui para aprofundar o debate sobre esse movimento no contexto brasileiro e latino-americano. Argumenta-se aqui que ele busca criar novas narrativas sobre o que seria gênero, buscando legitimação não só em espaços religiosos, mas também em espaços laicos, tal como na produção científica.

Com exceção dessa parte introdutória e das considerações finais, esse artigo será dividido em três outras partes: um primeiro momento, em que serão expostos e debatidos os referenciais teórico-metodológicos e os resultados quantitativos da investigação; um segundo momento, em que serão mapeados os estudos acadêmicos sobre o slogan "ideologia de gênero"; e, finalmente, uma terceira parte, em que será discutida a intersecção entre "ideologia de gênero" e produção de conhecimento.

\section{Metodologia da revisão ou de onde vêm as nuvens carregadas}

De acordo com Treinta et al (2014), a pesquisa bibliográfica é um dos problemas mais sérios a serem equacionados por pesquisadores. Desde a decisão cronológica até a organização da relevância do recorte temático,

\footnotetext{
[...] cabe ao pesquisador estabelecer uma estratégia de pesquisa bibliográfica que tanto facilite a identificação dos principais trabalhos em meio a uma quantidade grande de possibilidades que permeiam a produção científica mundial, como garanta a capacidade de estabelecer as fronteiras do conhecimento advindo dos achados científicos. (TREINTA et al, 2014, p. 508).
}

Desse modo, seria necessário que fossem estabelecidas estratégias que facilitassem a identificação e o diálogo com as questões de pesquisa propostas pelo pesquisador ou pela pesquisadora. Para esses autores, a metodologia que permitiria a maior otimização seria a revisão bibliométrica, na qual são usadas referências da matemática e da estatística de modo a organizar e analisar quantitativamente os dados obtidos. Ainda assim, tomando os estudos pós-estruturalistas como referência para esse artigo, assume-se aqui que:

[...] 'metodologia' é um termo tomado em nossas pesquisas de modo bem mais livre do que o moderno atribuído ao termo 'método'. Entendemos metodologia como um certo modo de perguntar, de interrogar, de formular questões e de construir problemas de pesquisa que é articulado a um conjunto de procedimentos de coleta de informações - que, em congruência com a própria teorização, preferimos chamar de 'produção' de informação - e de estratégias de descrição e análise. (MEYER, PARAÍSO, 2012, p. 16). 
Desse modo, "aproximamo-nos daqueles pensamentos que nos movem, colocam em xeque nossas verdades e nos auxiliam a encontrar caminhos para responder nossas interrogações" (MEYER, PARAÍSO, 2012, p. 16-17). Para tanto, exercita-se aqui a bricolagem metodológica, como proposta por Dagmar Meyer e Marlucy Paraíso (MEYER, PARAÍSO, 2012), em que são recortadas, borradas e costuradas metodologias de modo a adequá-las pensando em potencializar nossas pesquisas e nossos debates. Esse trabalho, assim, afasta-se da rigidez de uma escolha metodológica para construir um caminho próprio. Uma vez que o objetivo se focava em uma revisão de literatura, então, foram necessárias investigações de diferentes estudos sobre o assunto, bem como sobre revisão bibliométrica e estado da arte, de modo a potencializar a produção do material empírico para essa pesquisa, conjuntamente a sua análise. Foi adaptado, então, um método de produção do material empírico já utilizado anteriormente (ANDRADE et al, 2019), que parece potente para o caso, pois utiliza de duas estratégias principais: a permuta e a revisão inversa.

Nesse sentido, foram utilizadas plataformas online para a busca da produção científica sobre "ideologia de gênero", quais sejam: Scielo, Biblioteca Digital de Teses e Dissertações (BDTD) e Catálogo de Teses e Dissertações da Coordenação de Aperfeiçoamento de Pessoal de Nível Superior ${ }^{3}$ (CAPES). Na busca por artigos, dissertações e teses sobre o assunto, foi empregada a estratégia da permuta, como utilizada por Anderson Neves et al (2014), de modo a aumentar o alcance nas plataformas online. Tal estratégia consiste em cruzar (ou permutar) dois ou mais descritores nesses campos de pesquisa, que por vezes podem ser similares, mas que escapam dos filtros de busca por algumas letras diferentes. Desse modo, foram utilizados em permuta os descritores "Ideologia" e "Gênero", bem como "Ideológico" e "Gênero" e "Ideologia", "Gênero" e "Educação" e suas respectivas traduções em inglês e espanhol, de modo a obter um alcance mais amplo.

A restrição cronológica quase não criava diferença no resultado das buscas, uma vez que a ocorrência em publicações científicas foi mapeada entre 1998 e 2018 . Tal uniformidade ocorre porque foi em 1998 que "ideologia de gênero" teve a sua primeira menção em um documento eclesiástico oficial destinado ao público, na Conferência Episcopal Peruana (JUNQUIERA, 2017). A partir dessa produção de material empírico, foram encontrados sessenta e oito (68) materiais acadêmicos sobre o assunto, entre artigos, teses e dissertações.

De modo a ampliar ainda mais as possibilidades de alcance das buscas, foi utilizada também a revisão inversa. De acordo com Ana Marote et al (2012, p. 3), a revisão inversa é "um método de seleção de documentos a partir da bibliografia dos estudos primários, onde se procuraram artigos utilizados por esses mesmos estudos, remetendo-se, então, para uma pesquisa de literatura que não se encontra disponível a partir de bases de dados científico". Desse modo, a partir da leitura das sessenta e oito produções que já havia localizado, foram buscados entre eles referenciais que se repetiam e que não estavam em minha primeira busca. Com isso, foram adicionadas seis novas produções à lista ${ }^{4}$.

A partir dessa produção de material empírico para a análise, a argumentação deste artigo foi dividida em dois pontos: o primeiro, de caráter quantitativo, será descrito a seguir nesse subtítulo, em que é catalogada a produção acadêmica em critérios de localidade, área de estudos e ano da publicação. O segundo ponto, de caráter qualitativo, trata-se uma organização das linhas argumentativas lidas e será desenvolvido no subtítulo posterior.

\footnotetext{
${ }^{3}$ Visto que essa plataforma não possui ferramentas de pesquisa avançada, as buscas nela avançavam até as páginas vinte e cinco (25) de cada pesquisa.

${ }^{4}$ Cabe citar, porém, que foram procurados mais referenciais comuns, mas muitos deles não estavam disponíveis em plataformas ou em bibliotecas online.
} 
Dos setenta e quatro materiais analisados, cabe citar que a preponderância da forma de publicação é de artigos, que somaram cinquenta e nove do montante total. A seguir, vieram dissertações, apenas seis; capítulos de livros ou anais de eventos, somente três de cada; duas teses e uma produção que não se encaixa em nenhuma das categorizações anteriores. Dessa produção sob forma de artigos, inclusive, é notória a presença de dossiês, que configuram mais de metade das publicações e foram realizados por revistas de diversas áreas, quais sejam: as revistas Sexualidad, Salud y Sexualidad, Religion \& Gender, Dikaion, Cadernos Pagu e Ex Aqueo, que são publicadas, respectivamente, no Brasil, nos Países Baixos, na Colômbia e em Portugal. Por conta disso, a predominância desses textos é das regiões nas quais as revistas são sediadas, conforme se vê na figura abaixo:

Figura 1 - Países de publicação da produção localizada.

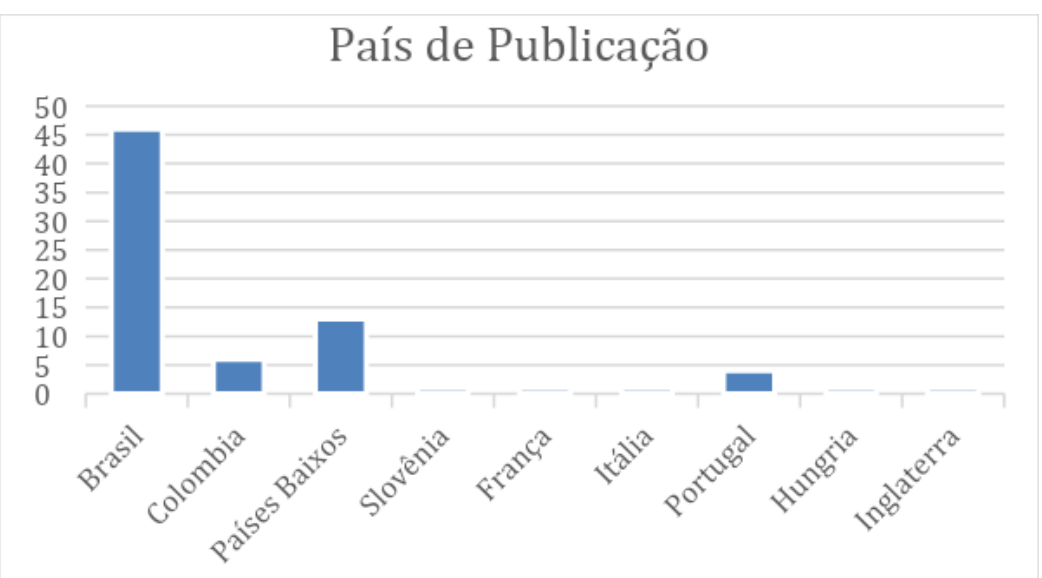

Fonte: Barzotto (2020).

Os países do quadro que aparecem nominados possuem pelo menos uma publicação em cada, mas suas porções gráficas - diante do número de publicações brasileiras - ficaram muito diminuídas. No Brasil, que desponta com uma grande produção bibliográfica sobre o assunto, há também desigualdade nessa produção, conforme pode ser observado na figura abaixo:

Figura 2 - Número de publicações por estado brasileiro.

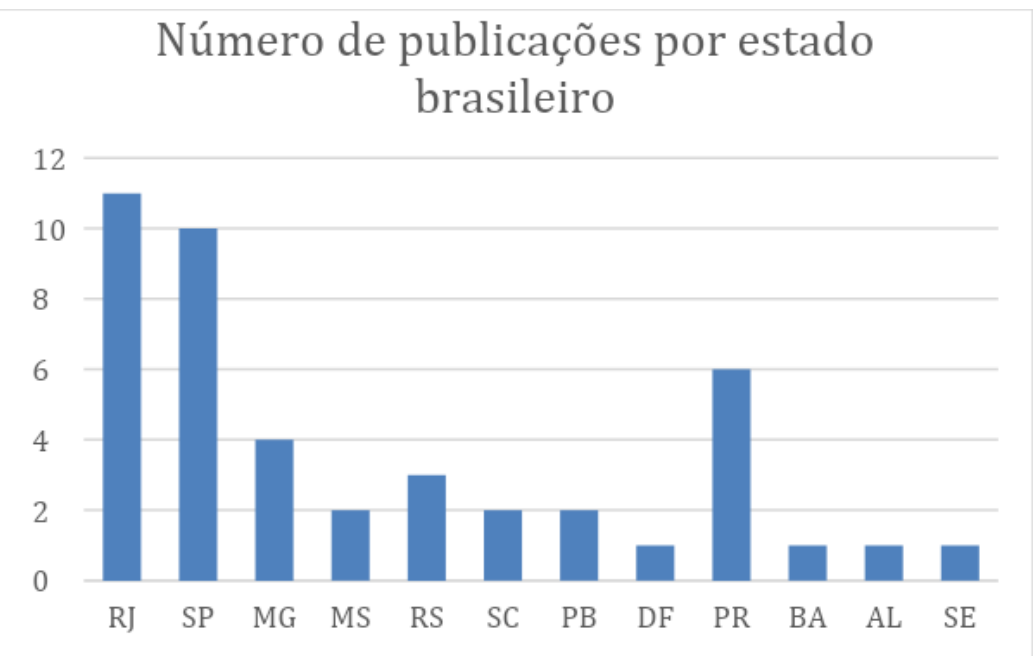

Fonte: Barzotto (2020). 
Os estados de São Paulo, Rio de Janeiro e Paraná destoam do resto do país no número de publicações. No caso dos dois primeiros, por serem os estados nos quais duas revistas que fizeram dossiês sobre o assunto estão localizadas. O Paraná, por outro lado, está ligado a ação de professores de universidades locais, pois a maioria desses números é advindo de teses, dissertações e/ou artigos realizados entre orientador/a e orientando/a de pós-graduação.

A representação numérica que mais interessa para o argumento que será defendido ao longo do artigo, porém, diz respeito ao pertencimento do campo de cada pesquisador e pesquisadora. Somando as autorias das publicações, foram contabilizados nomes de 84 autores e autoras em nível global, dos quais 50 são do nível nacional. Categorizando cada um deles de acordo com a área de conhecimento de sua titulação mais alta, a distribuição gráfica dessas áreas em nível global está representada na Figura 3:

Figura 3 - Área de Estudos dos Autores e Autoras

\section{Área de Estudos dos Autores e Autoras}

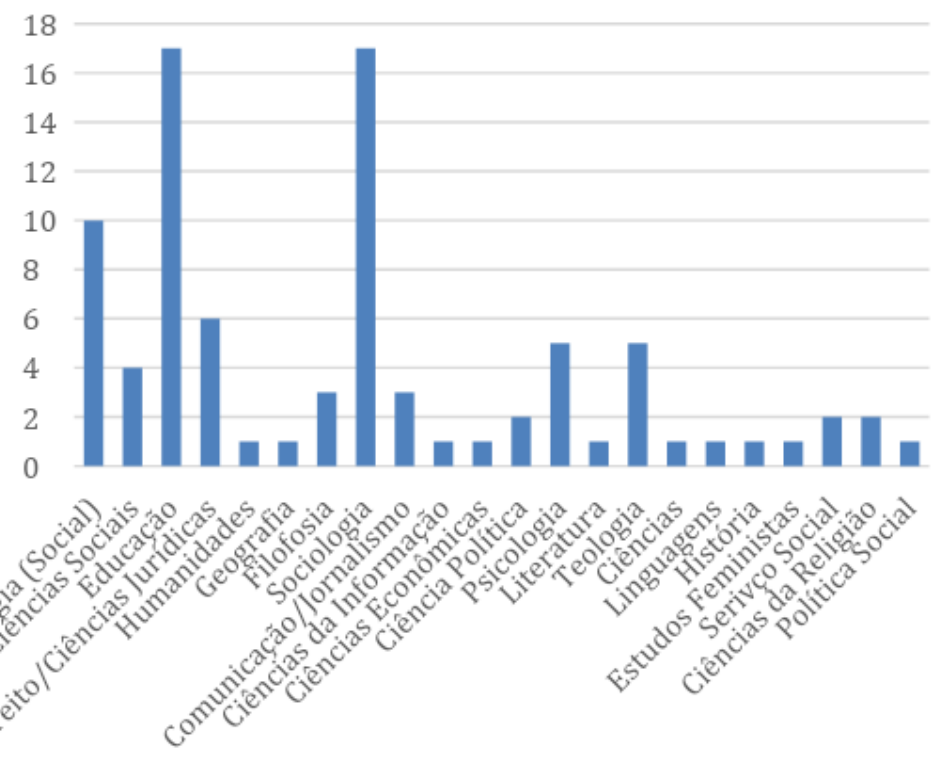

Fonte: Barzotto (2020).

Isso significa, em nível global, que as áreas de Sociologia, Educação e Antropologia (ou Antropologia Social) são as que mais têm interesse sobre a temática "ideologia de gênero". Ao aproximar esses números apenas das produções brasileiras, análises interessantes podem ser feitas. Isso porque quinze (15) dos dezessete (17) autores pertencentes ao campo da Educação são brasileiros, ao passo que nas outras áreas, como na Sociologia e na Antropologia, a predominância é similar entre brasileiros e estrangeiros ou tende para o lado dos últimos. Desse modo, parece haver maior interesse de pesquisadores de educação brasileiros sobre o assunto.

Para o escopo desse artigo, é de extrema importância questionar o porquê dessa presença. Será argumentado aqui que essa aproximação se dá por conta da forte presença do movimento contra a chamada "ideologia de gênero" nas instâncias educacionais brasileiras (SILVA, CÉSAR, 2017), bem como por conta de uma estreita aliança forjada com quase 
exclusividade no caso brasileiro, entre o movimento antigênero e o Movimento Escola Sem Partido (MIGUEL, 2016). Supõe-se, assim, que essa aproximação não é apenas por interesses de pesquisa, mas também por questões de urgência: diferente dos países europeus e do resto dos países norte-americanos, no Brasil o movimento antigênero - agrupado sob o nome da "ideologia de gênero" - ataca pilares da educação democrática de forma extremamente próxima do movimento Escola Sem Partido, criado por Miguel Nagib em 2004. Por conta desse ataque conjunto, sua inserção na área da Educação é catalisada e, assim, chama atenção de pesquisadores e pesquisadoras - seja pelo interesse de pesquisa ou pela urgência da temática.

\section{Ventos opostos: estudos anti/de gênero analisam a "ideologia de gênero"}

Jane Austen inicia seu célebre romance Orgulho e Preconceito, considerado por muitos(as) uma crítica à sociedade inglesa em que vivia, com a frase "é uma verdade universalmente conhecida que um homem solteiro, possuidor de uma boa fortuna, deve estar necessitado de esposa" (AUSTEN, 1982, p. 7). Nesse excerto, Austen tanto se apropria como também transforma em sátira discursos sobre masculinidades e sobre feminilidades presentes em sua sociedade. Apesar de não citar "gênero" - pois a categoria de análise, nesse momento, não fora cunhada -, ela já movimenta discursos e expectativas sociais em relação a corpos sexuados. Tal ímpeto poderia ser rastreado com frequência na história, uma vez que a resistência à tentativa de docilização e padronização de corpos está prevista na própria norma que busca padronizar esses corpos.

No campo acadêmico, como aponta Joan Scott (1995), seria possível rastrear esse movimento nas ações de acadêmicas feministas que iniciaram a procurar a presença feminina nas ciências, como na história (a História das Mulheres) e na filosofia. A partir da década de 70, porém, as acadêmicas feministas encontraram, conforme Scott, uma nova forma de pensar os corpos sexuados: o gênero. Com esse movimento, buscava-se enfatizar o caráter cultural da desigualdade entre homens e mulheres, escapando do essencialismo e da determinação biológica. De lá para cá, como argumenta Dagmar Meyer (2004, p. 14),

\footnotetext{
[...] as estudiosas feministas levaram para a academia temas e fontes de investigação até então concebidos como menores e não autorizados pelo paradigma científico vigente, podendo-se mencionar temáticas e fontes vinculadas ao cotidiano, à família, à sexualidade e ao trabalho doméstico, dentre outras. Tais abordagens e objetos vêm sendo introduzidos, também, de forma paulatina e nem sempre harmoniosa, em agendas curriculares e de pesquisa de inúmeros campos disciplinares e profissionais de diferentes níveis de ensino e instituições.
}

A categoria "gênero", assim, vem sendo utilizada de modo a problematizar a forma como nossa sociedade se organiza; e a essa categoria une-se também a categoria "sexualidade" (LOURO, 1997). Ambas as categorias são advindas de movimentos sociais, sejam feministas, sejam LGBTQIA+, e já produziram suporte teórico e filosófico para uma série de ações político-sociais, bem como ecoaram as vozes dos movimentos sociais ao questionarem padrões sociais previamente estabelecidos. Grandes exemplos dessas movimentações, que partem de movimentos sociais da sociedade civil e que não estão necessariamente na academia, são as articulações internacionais feitas junto à Organização das Nações Unidas (ONU), como a Convenção sobre a Eliminação de Todas as Formas de Discriminação Contra a Mulher (1979) e a IV Conferência Mundial sobre as Mulheres (1995). 


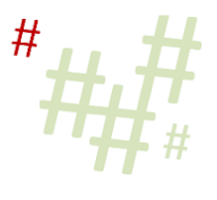

Essas convenções e conferências articulam vozes de movimentos sociais do mundo inteiro e propõem formas de superar desigualdades sociais através de plataformas de ação, das quais uma série de países são signatários, incluindo o Brasil.

A partir do início do século XXI, o Brasil encaminhou-se a passos largos para a criação de políticas que respeitassem essas plataformas e convenções. No campo dos direitos das mulheres, foram feitas quatro Conferência Nacional de Políticas para as Mulheres (2004, 2007, 2011, 2016), que resultaram em três Planos Nacionais de Políticas para as Mulheres (2005, 2008 e 2013). No campo dos direitos da população LGBTQIA+, também foi lançado, em 2004, o programa Brasil Sem Homofobia. Ambos os exemplos representam tentativas, por parte do Estado, de diminuir as desigualdades de gênero e de sexualidade.

Ao mesmo tempo em que esse movimento acontecia no Brasil e no mundo, no entanto, preparava-se uma virada ultraconservadora: como argumenta Rogério Junqueira (2017), a Igreja Católica começaria a reagir a essas ações, categorizando-as como uma "cultura de morte", opondo-se às questões relacionadas ao aborto, ao casamento homoafetivo, à eutanásia e ao ensino de educação sexual nas escolas. Fortalecido dentre o Conselho Pontifício para a Família e de Conferências Episcopais, entre 1990 e 2000, essa virada:

[...] visa, além de recuperar espaço à Igreja em sociedades envolvidas em distintos processos de secularização, conter o avanço de políticas voltadas a garantir ou ampliar os direitos humanos de mulheres, pessoas não-heterossexuais e outros dissidentes da ordem sexual e de gênero. Para tanto, tais cruzados morais investem maciçamente na (re)naturalização das concepções de família, maternidade, parentesco, (hetero)sexualidade, diferença sexual. Deste modo, procuram também promover a restauração ou, mais propriamente, o aggiornamento do estatuto da ordem sexual tradicional e reforçar as disposições relativas às normas de gênero, à heterossexualidade obrigatória e à heteronormatividade. (JUNQUEIRA, 2017, p. 26).

Seria um erro, no entanto, localizar o movimento antigênero como apenas católico ou apenas religioso. Nesse sentido, Sara Garbagnoli (2016) argumenta que o sucesso dessa cruzada antigênero e, portanto, de sua proliferação ao redor do mundo dá-se a partir da combinação de dois elementos: as especificidades do próprio discurso antigênero e a adaptação da sua retórica ao contexto nacional de cada país.

Valendo-se das teorizações de Ernesto Laclau, então, Kuhar e Zobec (2017) categorizam "ideologia de gênero" como um significante vazio: um enunciado vazio, ao qual podem se aglutinar outros de acordo com a necessidade ou intenção. Dessa forma, pode-se categorizar o movimento antigênero como transacional. No entanto, como pontua Garganoli (2016), ele se ajusta às especificidades nacionais de modo a impulsionar-se. Nesse contexto, é importante questionar: de que modo os pesquisadores da área da educação localizam esse debate? Quais as características e estratégias discursivas atribuídas ao movimento antigênero que se organiza em torno do slogan "ideologia de gênero"?

Em 2018, Ivanderson Silva (2018) buscou também fazer uma revisão de literatura sobre o assunto, a partir de resultados encontrados no Google Acadêmico, que somavam 26 publicações. Uma vez que o escopo quantitativo aqui analisado é maior, gostaria de rever algumas questões pontuadas por Silva, de modo a potencializar seus resultados. Segundo ele, as produções científicas sobre "ideologia de gênero" têm quatro significados principais. O primeiro deles vê machismo e LGBTfobia como ideologias de gênero, partindo do pressuposto de que formações culturais sobre gênero e sexualidade configuram corpos e, 
portanto, seriam ideologias. Para tais publicações, então, a determinação do uso da cor rosa para corpos femininos seria, nesse sentido, uma ideologia de gênero. Na pesquisa aqui apresentada, tal categoria encontrou eco, pois algumas publicações que utilizavam "ideologia de gênero" em suas palavras-chave, títulos ou resumos encaixavam-se nessa utilização. Assim, utilizavam-no como conceito científico, e não como slogan.

A segunda e a terceira categorias são próximas, e dizem respeito às visões de ideologia de gênero como prelúdio do apocalipse moral. No primeiro caso, visto a partir dos olhos eclesiásticos; e, no segundo, visto a partir de atores políticos brasileiros, como Miguel Nagib e Jair Messias Bolsonaro. Nessas publicações,

\footnotetext{
"Ideologia de Gênero" foi analisado como um conjunto de ideias falsas, de origem marxista, que tem como objetivo destruir a família natural, estimular todos os tipos de libertinagem sexual, incluindo uniões homossexuais, pedofilia, zoofilia e necrofilia. (SILVA, 2018, p. 7).
}

Para a quarta categoria, finalmente, "ideologia de gênero" é visto como falácia, cuja origem vaticana e manipulativa pode e está sendo exposta pelo discurso científico. Assim, para Silva (2018), essa quarta categoria de publicações desmascara a falsidade do discurso religioso. Nesse ponto, encaixar-se-iam a grande parte dos artigos, teses e dissertações que foram rastreados online, visto que as plataformas procuram apenas publicações científicas.

Ainda assim, mesmo dentre esses textos, argumenta-se aqui que foi encontrado um grupo de publicações supostamente acadêmicas que se utilizam do discurso criado pelo Vaticano de modo a impulsionar o movimento antigênero, sobretudo na América Latina. Por conta disso, acrescenta-se uma categoria a mais a divisão de Silva (2018): junto à utilização de "ideologia de gênero" como conceito, às visões de "ideologia de gênero" como prelúdio do apocalipse, e às tentativas de evidenciar as falácias discursivas do movimento antigênero, poderíamos acrescentar a categoria dos estudos antigênero pretensamente científicos.

As publicações que foram encontradas e que estariam relacionadas a categoria de estudos antigênero proposta estão localizadas, por exemplo, nas publicações da revista Díkaion, da Universidad La Sabana, na Colômbia, cujo foco são as áreas do Direito. Nela, uma série de autores e autoras - frequentemente europeus e europeias - publicaram artigos que buscavam desmantelar teoricamente os suportes das teorizações de gênero, em especial de Judith Butler, alinhando - por vezes - esses estudos aos estudos marxistas. Além de adaptar o discurso antigênero do contexto europeu para o latino-americano, essas publicações também devem ser vistas como importantes, pois como defendem Paternotte e Kuhar (2017, p. 6),

\footnotetext{
Campanhas antigênero também podem ser lidas como um projeto de produção de conhecimento alternativo, que tem como objetivo desmantelar a pesquisa pós-estruturalista nas ciências sociais e nas humanidades em particular. As últimas são consideradas ideológicas e desconectadas das supostamente inquestionáveis descobertas das ciências naturais, especialmente de estudos biológicos, médicos e psicológicos alinhados com a ideia de existências essenciais entre homens e mulheres (incluindo diferenças entre cérebros masculinos e femininos) e a complementaridade deles.
}

Desse modo, então, neste artigo discorda-se do que argumenta Silva (2018): não há apenas uma produção científica sobre gênero, que desmascarará o slogan de origem vaticana. 
Do mesmo modo, o movimento antigênero não se articula apenas em campos eclesiásticos ou da política institucional, uma vez que ele capilariza-se por uma série de ambientes, buscando legitimidade para si onde puder encontrar. Há, nesse sentido, uma disputa pelos conceitos de gênero e sexualidade no campo científico (ou pretensamente científico) e da produção de conhecimento de um modo geral.

Nesse sentido, ser potente o aporte conceitual de Michel Foucault (2013). Para ele, as ciências - e os discursos científicos - constituem-se enquanto reguladoras e produtoras de verdades - tanto em seu interior quanto em seu exterior -, garantindo discursivamente suas legitimidades. Não estaria, assim, o movimento antigênero buscando sua legitimidade em discursos pretensamente científicos? Isso não significa que tal movimento queira necessariamente criar diálogos no meio acadêmico, mas sim que ele vê a necessidade de se fundamentar em regimes de verdade para legitimar seu discurso. $\mathrm{O}$ movimento antigênero, portanto, disputa o que é verdade sobre "gênero" ao criar uma nova narrativa sobre o que seria ele, bem como sobre o que seria a sexualidade. Desse modo, conforme argumenta Rogério Junqueira (2017), que existe, sim, uma ideologia de gênero. Desse modo,

\footnotetext{
"Teoria/ideologia de gênero", portanto, existe e não corresponde e nem tampouco resulta do campo dos Estudos de Gênero ou dos movimentos feministas e LGBTI. É, em vez disso, um dispositivo de origem vaticana urdido para promover uma agenda ultraconservadora, antifeminista e antagônica à democracia e aos direitos humanos entendidos em bases mais amplas e plurais. (JUNQUEIRA, 2017, p. 46).
}

Argumenta-se nesse artigo, portanto, que os estudos antigênero disputam regimes de verdade e, portanto, de poder, com os atuais estudos acadêmicos sobre gênero e sexualidade. Eles operam discursivamente, assim como o movimento de base não acadêmica, para frear a secularização ocorrida na Europa e, sobretudo, na América Latina desde as décadas de 1980 e 1990. Não é por acaso que, em escala global, esse movimento antigênero tenha sido marcado, como defende Amanda Silva (2017, p. 107), "pelo aparecimento de um discurso bio-religioso com pretensões de cientificidade". Por conta disso, serão debatidas, no tópico a seguir, algumas características da retórica presente nos artigos encontrados na revista Dikaion nessa revisão bibliográfica.

\section{Relâmpagos e trovões: "ideologia de gênero" e o embate (pretensamente) científico}

Foi argumentado anteriormente que a retórica do movimento antigênero busca estender-se a outras arenas da sociedade, como as mais secularizadas. Busca-se, enfim, compreender como se dá essa relação no caso da produção de conhecimento (pretensamente) científico. Nesse sentido, é potente pensar que o uso da biologia e da religião em conjunto compõem uma retórica não completamente secular, mas também não completamente religiosa. Isso porque, conforme pontua Romain Carnac (2014, p. 131 - tradução minha), "o discurso católico aposta claramente na vontade de alcançar uma audiência maior que apenas seu círculo de crentes. Ele se dirige, de acordo com a fórmula desejada, a todos os "homens de bem" $[\ldots] "$ ".

Analisando o caso croata, por exemplo, Amir Hodžic e Aleksandar Štulhofer (2017) propõem que a retórica em torno do sintagma "ideologia de gênero" nega uma parte da ciência e uma parte da retórica secular, mas ao mesmo tempo as abraça. Nesse sentido, por exemplo, utiliza-se da biologia para negar a existência de corpos trans, uma vez que, de 
acordo com suas argumentações, não seria possível mudar a constituição natural dos corpos. Ao mesmo tempo, recusam-se as teorias evolucionistas. Então, tal retórica faz parte do que Amanda da Silva e Maria Rita (2017, p. 211) chamam de discurso bio-religioso e antigênero, que "almeja uma continuidade entre o sistema sexo-gênero-desejo e está centrado nos aspectos psicológicos e comportamentais da criança".

Um dos focos principais do movimento antigênero tem sido, nesse sentido, a identidade de gênero (SEFFNER, 2016), tomada por atores desse movimento como uma invenção de educadores que querem doutrinar crianças em idade escolar. Em oposição à identidade de gênero, portanto, os partidários da luta antigênero defendem que: [...] a identidade do sujeito é definida a partir do nascimento no sexo masculino ou
feminino. Ou seja, não existe para este grupo a ideia de construção social dos papéis
de gênero. O sexo biológico determinaria necessariamente a identidade de gênero.
Para sustentar esta noção os agentes religiosos utilizaram prioritariamente como
referência "especialistas" e profissionais da área da saúde, como o Dr. Christian
Schnake, médico chileno e especialista em Bioética [...] (MENDONÇA, 2017, p.
178).

Tomam-se, assim, os discursos da área da saúde para (re)construir noções embasadas na "naturalidade" do sexo biológico (MENDONÇA, 2017). Tais discursos biológicos são os mesmos que, para Michel Foucault (FOUCAULT, 2013), ganharam notoriedade na transição para a contemporaneidade por conseguir, por meio de relações de poder, mostrarem-se como verdades únicas, absolutas e, sobretudo, naturais. Ao repetir os discursos biomédicos e legitimá-los como verdades únicas, eles tornam-se naturalizados e, além disso, vistos como irrefutáveis. Oposição feita a eles seria, portanto, uma ilusão discursiva e/ou imaginada, que é precisamente como os representantes do movimento antigênero caracterizam os estudos de gênero.

Desse modo, em consonância com a argumentação de Maria Rosado-Nunes (2015, p. 1252), defende-se aqui que: "[...] o conceito de "natureza humana" como decorrente de uma "lei natural" dada por Deus, comprovada pela biologia e inalterável é peça fundamental na argumentação que sustenta a condenação do gênero qualificado como uma "ideologia", com forte conotação negativa". Ao utilizar de certas argumentações de forma seletiva, o movimento antigênero obtém sucesso ao causar uma série de pânicos morais (BORGES, BORGES, 2018) que estimulam seu crescimento em arenas não religiosas. $O$ caso da mamadeira referida na introdução, bem como o livro supostamente utilizado pelo Ministério da Educação, são exemplos: não se fala no divino ao enunciar aquelas declarações, pois trata-se de uma retórica que forma um discurso mais complexo e semi-laico. Ainda assim, essa retórica tem origem e dá suporte para lógicas (ultra)conservadoras, como as gestadas no Vaticano.

No caso das publicações da revista Dikaion, a insistência no discurso biológico é central, mesmo que se trate de um período da área jurídica. De acordo com os autores dessas publicações, o chamado "feminismo de gênero" é radical por negar a biologia de corpos ditos masculinos e femininos. Nessa visão, segundo eles,

[...] el género se caracteriza, fundamentalmente, por su radical autonomía con respecto al dato biológico, por su elaboración al margen de todo presupuesto empírico o natural. Se sostiene así que cualquier diferencia entre varón y mujer responde, íntegramente, al proceso de socialización e inculturación. En esta línea, y 
en general, muchas propuestas del posfeminismo de género parten de la defensa de la absoluta irrelevancia del sexo biológico en los ámbitos personal, social e, incluso, jurídico. (APARASI-MIRALLES, 2012, p. 362).

Assim, a retórica antigênero estabelece discursivamente dois polos: o da visão dos corpos como naturais e biológicos ou como culturais e sociais. Desse modo, os estudos de gênero - chamados por eles de "ideologia de gênero" - estariam anulando "cualquier presupuesto objetivo en la identidad sexual humana" (APARASI-MIRALLES, 2012, p. 362). Do mesmo modo, esses autores e autoras referem que aquilo que chamam de (pós-)feminismo teria ido longe demais ao supostamente afirmar uma igualdade absoluta. Nessa igualdade absoluta, o (pós-)feminismo pretenderia abolir a principal diferença entre os corpos sexuais: a maternidade. Assim, os "ideólogos de gênero" (como são chamados os proponentes de estudos de gênero) veriam a maternidade como:

[...] una enfermedad o incluso como una carga impositiva que el sistema patriarcal o
androcéntrico, como suelen referirse a la historia, le ha impuesto a la mujer. así, para
un ideólogo de género, la maternidad se reduce a la carga reproductiva que el
hombre le ha impuesto a la mujer, la cual debe ser abolida, por lo que empiezan a
plantearse unos supuestos derechos que intentarían equilibrar la balanza, tal es el
caso del aborto, la anticoncepción o la esterilización, impulsados bajo el nombre de
"planificación familiar" o "derechos sexuales y reproductivos.
(CAMPILLO-VÉLEZ, 2013, p. 27).

Percebe-se, então, que um dos gatilhos discursivos para mobilizar o discurso antigênero na América Latina é o perigo do fim da maternidade e, com ela, do fim da família cristã. Com tal caráter alarmista, essas publicações também buscam categorizar o movimento feminista com base em seu histórico e com base em algumas leituras essenciais que o baseiam.

Ângela Aparisi-Miralles, por exemplo, diferencia o feminismo da equidade e o feminismo de gênero, sendo que o primeiro lutaria pela igualdade legal e jurídica entre os sexos, ao passo que o segundo tem "unos objetivos más amplios aspirando a un cambio social y jurídico más profundo, a un nuevo y revolucionario modelo de sociedad" (APARISI-MIRALLES, 2012, p. 365). A partir de citações de outros sujeitos que teriam estudado Filosofia, Direito e Sociologia, a autora conclui que o feminismo de gênero está alinhado ao existencialismo de Jean-Paul Sartre, ao "pansexualismo de la izquierda freudiana" (idem), ao marxismo, ao evolucionismo, ao desconstrucionismo, ao hedonismo e, finalmente, à teoria queer, cujo ápice de ação foram as conferências da Organização das Nações Unidas (ONU) entre das décadas de 1980 e 1990. Desse modo, ela coloca-se enquanto feminista (da equidade) e repudia o que chama de feminismo de gênero, considerando-o uma invasão de ideias estrangeiras.

Seguindo as divisões do feminismo, Rafael D’Angelo (2013) faz a releitura de sistemas de sexo-gênero propostos pelo feminismo e propõe, enfim, um terceiro próprio. $\mathrm{O}$ primeiro, chamado poder ele de identidade entre sexo e gênero, é o tradicional, que vê o biológico como regra para os corpos sexuados. O segundo, chamado por ele de independência entre sexo e gênero, repete a percepção alarmista de que o feminismo negaria a biologia completamente. E, enfim, o terceiro, chamado de interdependência e corresponsabilidade, busca um equilíbrio entre os dois primeiros. Nele, homens e mulheres cooperam entre si e 
complementam-se na realização de suas tarefas sociais, apesar de manterem distintas tarefas biológicas, como a gravidez. Nesse sentido, segundo ele,

[...] en esta mutua cooperación hay que distinguir funciones intercambiables, es decir, que pueden ser realizadas indistintamente por personas de ambos sexos, y que dependen solo del aprendizaje, frente a roles que están conectados a una diferenciación biológica y que no son transferibles al otro sexo. (D'ANGELO, 2013, p. 291).

Foi exemplificada, aqui, a argumentação das publicações da revista porque ela permite evidenciar não só a relação dos autores e autoras com uma pretensão científica, mas também sua relação com a retórica antigênero de origem vaticana. Como defendem Mary Case (2016) e Rogério Junqueira (2017), por exemplo, uma mudança discursiva importante na Igreja Católica foi a adoção da teologia da complementaridade, em que homens e mulheres são vistos socialmente iguais, mas biologicamente diferentes - complementando-se igualitariamente em suas tarefas biologicamente distintas, assim como postula a proposição de D’Angelo (2013).

Sua proposição acerca da complementaridade natural dos sexos - alinhada com a Igreja - é, para ele, uma "perspectiva capaz de mostrar la integridad del ser humano en su dimensión individual y social y, al mismo tiempo, en la necesaria complementariedad $-\mathrm{y}$ corresponsabilidad - entre el varón y la mujer" (D’ANGELO, 2013, p. 274). É importante perceber, então, que a retórica antigênero empregada nesse discurso busca legitimidade em publicações científicas, assim como utiliza de características de uma publicação - de forma parcial. As citações de outros pesquisadores, nesse sentido, oscilam entre autores e autoras que tenham proposto algum conceito científico (sobretudo da área jurídica) e autores e autoras eclesiásticos, como o argentino Jorge Scala, que propõe que o Estado está colocando a sociedade em risco ao adotar perspectivas de gênero (LIONÇO et al, 2018). Além disso, raras são as citações que atestam afirmações sobre a biologia, o que nos leva a crer que elas são tomadas como naturais na ordem daquele discurso, conforme foi argumentado anteriormente.

Cabe pontuar, enfim, uma última questão. Na retórica pretensamente científica enunciada nas publicações analisadas, muitas são as menções a documentos ditos oficiais e conspiratórios que revelariam planos, como o plano dos Estados Unidos de implantar os Direitos Humanos em todas as sociedades (CAMPILLO-VÉLEZ, 2013). Tal argumentação alarmista pode utilizar conceitos científicos, mas isso não significa que os utiliza com rigor científico.

Nesse sentido, cabe citar que a argumentação nessa retórica bio-religiosa não é apenas biológica, como também é jurídica. Não se trata apenas de fundamentar-se na biologia, como também no Direito para legitimar-se, pois, sendo o discurso antigênero semi-laico, ele necessita dialogar com as estruturas e sujeitos laicos da sociedade. Desse modo, documentos oficiais e não oficiais são citados como comprovantes de conspiração global, assim como estudos legitimados ou não pela academia também são colocados como igualmente comprovantes da suposta ameaça à família. Nesse sentido, por exemplo, que Campillo-Vélez (2013) denuncia o que chama "infiltração" da "ideologia de gênero" no Direito colombiano a partir de documentos conspiracionistas, assim como Aparisi-Miralles (2012) denuncia o que ela chama de deslegitimização jurídica da família tradicional da mesma forma. Trata-se, enfim, de uma retórica que combina o religioso ao supostamente científico e/ou laico em uma 
sociedade em processo de secularização. Com tal retórica pretensamente científica, busca-se alcançar legitimidade na arena pública e frente às populações.

\section{Considerações finais: abrindo guarda-chuvas?}

Neste artigo, buscou-se compreender algumas das relações que o discurso antigênero tem feito ao capilarizar-se na sociedade. Para tanto, foi realizada uma revisão bibliográfica buscando as principais chaves de leitura que têm sido empregadas para caracterizar o movimento e, desse modo, buscar os outros discursos com os quais ele se relaciona.

A partir da leitura de setenta e quatro materiais selecionados, na revisão bibliográfica, foi possível aprofundar as divisões propostas por Ivanderson Silva (2018). Desse modo, foi proposto neste trabalho que o sintagma/slogan "ideologia de gênero" também é usado para criar uma série de estudos e publicações pretensamente científicas - como as quatro publicações encontradas da revista Dikaion - que visam disputar os significados sobre "gênero" e "sexualidade" de modo a legitimar a retórica que afirma que esses últimos são perigosos para a sociedade e, então, estimular a criação de pânicos morais para frear o avanço da laicização e da secularização. Além disso, foi proposto que a utilização da retórica científica nesse discurso bio-religioso e semi-laico é também parcial, ora empregando conceitos academicamente formulados, ora utilizando-se de documentos eclesiásticos, ora fazendo afirmações não embasadas teoricamente por considerá-las naturais, como a biologia.

Foi considerado, ainda, que a análise dessa produção dita científica é de extrema importância para refletir sobre as relações entre o discurso religioso e o discurso científico comumente distanciados - e sua relação com as categorias de gênero e sexualidade. Tal estudo, porém, ainda é inicial. Ele necessita, para ampliar sua chave de leitura interpretativa, de maior análise, com mais documentos analisados e leituras específicas desse contexto.

Cabe citar, finalmente, a proposição de Paternotte e Kuhar (2016) no sentido de afirmar que o movimento antigênero não busca um retorno absoluto ao passado, e sim a criação de uma nova forma de cidadania futura, que poderia configurar-se no que Juan Vaggione (2017) chama de cidadania religiosa. O movimento antigênero representa, portanto, uma tentativa de construir novas formas de exercer a participação nas sociedades atuais, que estejam preferencialmente ligadas à moral cristã.

Essa tentativa de transformação das formas de viver a sociedade transforma também a ação no espaço público e, portanto, atinge um dos grandes espaços nos quais os jovens vistos como grandes vítimas da "ideologia de gênero" - vivem: a escola pública. Buscando aumentar a influência religiosa na ação cidadã, assim, o discurso antigênero entra em consonância com os movimentos que buscam reduzir a própria constituição democrática e cidadã da escola, como o Movimento Escola sem Partido (PENNA, 2017).

Nesse sentido, ele reforça a tendência da união entre o espaço público e o espaço privado, com privilégio desse último, de modo a criar uma sociedade em que o espaço público seja reduzido a criação de sujeitos não alinhados necessariamente à cidadania, mas sim à produtividade neoliberal (LAVAL, 2004). Por conta disso, o próprio direito público recua, em nome do direito privado, como ocorre em relação ao homeschooling. Exemplo disso é a argumentação de uma das autoras da revista Dikaion, comentada neste artigo, que afirma que a chamada "ideologia de gênero" "tiende a privar del ejercicio de la autoridad y del derecho fundamental a la educación de los hijos por parte de los padres" (APARISI-MIRALLES, 2013, p. 369). 
No Brasil, nesse sentido, utiliza-se de argumentação similar àquela do movimento antigênero para sustentar o projeto Escola Sem Partido e coibir a entrada dos estudos de gênero no campo escolar: ora com atividades parlamentares, ora com apelos à sociedade civil, ora com apelos à sociedade eclesiástica, o movimento ganha força. Com isso, os direitos de liberdade individual e educacional da família sobrepõem-se aos direitos de educação da criança e ao seu direito à socialização. Como defende Miguel (2016, p.603), "Estabelece-se, assim, uma hierarquia estrita entre família e escola, com o predomínio inconteste da primeira". Portanto, cabe que nos questionemos: de que forma o discurso antigênero está atravessado por todos esses outros na arena política? Quais as relações de poder entre eles? Qual é - e qual será - o papel da escola contemporânea frente a esses discursos? E qual é - e qual será - o papel do discurso científico nesse embate?

\section{Referências}

ANDRADE, Sandra dos S.; MEYER, Dagmar E. E.; BARZOTTO, Carlos E. Transversalidade de gênero em políticas públicas: uma revisão de literatura. Prâksis, Novo Hamburgo, v. 2, p. 81-106, 2019. Disponível em:

https://periodicos.feevale.br/seer/index.php/revistapraksis/article/view/1816. Acesso em 30 nov. 2019.

APARASI-MIRALLES, Ângela. Modelos de la relación sexo-género: de la "ideologia de género" al modelo de la complementaridad varón-mujer. Dikaion, Chía. v. 21, n. 2, p. 357-384, 2012. Disponível em: http://www.scielo.org.co/pdf/dika/v21n2/v21n2a03.pdf. Acesso em: 30 nov. 2019.

AUSTEN, Jane. Orgulho e Preconceito. Tradução de Lúcio Cardoso. São Paulo: Abril Cultural, 1982.

BORGES, Rafaela O.; BORGES, Zulmira N. Pânico moral e ideologia de gênero articulados na supressão de diretrizes sobre questões de gênero e sexualidade nas escolas. Revista Brasileira de Educação, Rio de Janeiro, v. 23, p. 1-23, 2018. Disponível em: http://www.scielo.br/pdf/rbedu/v23/1809-449X-rbedu-23-e230039.pdf. Acesso em: 30 nov. 2019.

CAMPILLO-VÉLEZ, Beatriz E. La ideologia de género en el derecho colombiano. Díkaion, Chía. v. 22, n. 1, pp. 13-54, p. 2013. Disponível em:

http://www.scielo.org.co/pdf/dika/v22n1/v22n1a02.pdf. Acesso em: 30 nov. 2019.

CARNAC, Romain. L'Église catholique contre "la théorie du genre": construction d'un objet polémique dans le débat public français contemporain. Synergies France, Gerflint, n 10, pp. 124-143, 2014.

CASE, Mary Anne. The Role of the Popes in the Invention of Complementarity and the Vatican's Anathematization of Gender. Religion \& Gender. v. 6, n. 2, p. 155-172, 2016.

D’ANGELO, Rafael S. M. Del género a la perspectiva de familia: elementos para una nueva proposta. Díkaion, Chia. v. 22, n. 2, p. 273-302, 2013. Disponível em:

https://www.redalyc.org/pdf/720/72031061005.pdf. Acesso em: 30 nov. 2019. 
ESTADÃO VERIFICA. “Mamadeiras eróticas” não foram distribuídas em creches pelo PT. Estadão, São Paulo, 28 set. 2018. Disponível em: https://

politica.estadao.com.br/blogs/estadao-verifica/mamadeiras-eroticas-nao-foram-distribuidas-e m-creches-pelo-pt/. Acesso em:30 ago. 2020.

FOUCAULT, Michel. A Arqueologia do Saber. Tradução Luiz Felipe Baeta Neves. 8. ed. Rio de Janeiro: Forense Universitária, 2013.

GARBAGNOLI, Sara. Against the heresy of Immanence: Vatican's 'Gender' as a New Rethorical Device Against the Desnaturalization of the Sexual Order. Religion \& Gender. v. 6, n. 2, p. 187-204, 2016.

HODŽIC, Amir; ŠTULHOFER, Aleksandar. Embryo, teddy bear-centaur and the constitution: Mobilizations against "gender ideology" and sexual permissiviness in Croatia. In: KUHAR, Roman; PATERNOTTE, David (org.). Anti-Gender Campaigns in Europe: Mobilizing against Equality. London, Rowman \& Littlefield Internacional Ltd, p. 59-78, 2017. (ebook).

JUNQUEIRA, Rogério Diniz. "Ideologia de Gênero": a gênese de uma categoria política reacionária - ou: a promoção dos direitos humanos se tornou uma "ameaça à família natural"?. In: RIBEIRO, Paula R. C.; MAGALHÃES, Joanalira C. (org.). Debates contemporâneos sobre Educação para a sexualidade. Rio Grande: FURG, p. 25-52, 2017.

KUHAR, Roman; ZOBEC, Aleš. The Anti-Gender Movement in Europe and the Educational Process in Public Schools. C-E-P-S Journal, Ycar, v. 7, n. 2. Pp. 29-46, 2017.

LAVAL, Christian. A Escola não é uma empresa: O neo-liberalismo em ataque ao ensino público. Londrina: Planta, 2004.

LIONÇO, T., ALVES, A. C. O., MATTIELLO, F., \& Freire, A. M. "Ideologia de gênero": estratégia argumentativa que forja cientificidade para o fundamentalismo religioso. Psicologia Política, v. 18, n. 43, p. 599-621, set./dez. 2018. Disponível em:

http://pepsic.bvsalud.org/pdf/rpp/v18n43/v18n43a11.pdf. Acesso em 30 nov. 2019.

LOURO, Guacira Lopes L. Gênero, sexualidade e educação: uma perspectiva pós-estruturalista. Petrópolis, RJ: Vozes, 1997.

MAROTE, Ana S. F.; PINTO, Carla A.; VIEIRA, Marlene R.; BARBIÉRI-FIGUEIREDO, Maria C. A.; PEDROSA, Pedro M. N. Crianças como cuidadoras: revisão integrativa. Rev. Latino-Am. Enfermagem, Ribeirão Preto, v. 20, n. 6, p. 1-10, 2012. Disponível em: http://www.scielo.br/pdf/rlae/v20n6/pt_23.pdf. Acesso em: 30 nov. 2019.

MENDONÇA, Amanda A. Estado, religião e democracia: reflexões a partir dos debates sobre "ideologia de gênero" no Plano Nacional de Educação. Tese (Política Social), Universidade Federal Fluminense, 2017. 249f.

MEYER, Dagmar E. E. Teorias e políticas de gênero: fragmentos históricos e desafios atuais. Revista Brasileira de Enfermagem, Brasília, n. 57, v. 1, p. 13-18., jan/fev. 2004. 
MEYER; PARAÍSO, Marlucy Alves. Apresentação. In: MEYER, Dagmar Estermann; PARAÍSO, Marlucy Alves (org.). Metodologias de Pesquisas Pós-Críticas em Educação. Belo Horizonte: Mazza Edições, p. 15-22, 2012.

MIGUEL, Luis Felipe. Da "doutrinação marxista" à "ideologia de gênero" - Escola sem Partido e as leis da mordaça no Parlamento brasileiro. Revista Direito \& Práxis, Rio de Janeiro, v. 07, n. 15, p. 590-621, 2016. Disponível em:

https://www.e-publicacoes.uerj.br/index.php/revistaceaju/article/view/25163. Acesso em 30 nov. 2019.

NEVES, Jonas Anderson das; ANTONELLI, Carolina de Santi; DA SILVA, Mariana Girotto Carvalho; CAPELLINI, Vera Lúcia Messias Fialho. Escolarização formal e dimensões curriculares para alunos com autismo: o estado da arte da produção acadêmica brasileira. Educação em Revista, Belo Horizonte, v. 30, n. 2, p. 43-70, 2014. Disponível em: http://www.scielo.br/pdf/edur/v30n2/03.pdf. Acesso em: 30 nov. 2019.

PARAÍSO, Marlucy A. Fazer do caos uma estrela dançarina no currículo: invenção política com gênero e sexualidade em tempos do slogan "ideologia de gênero". In: PARAÍSO, Marlucy A.; CALDEIRA, Maria C. da S. (org.). Pesquisas sobre currículos, gêneros e sexualidades. Belo Horizonte: Mazza Edições, p. 23-52, 2018.

PATERNOTTE, David; KUHAR, Roman. The anti-gender movement in comparative perspective. In: KUHAR, Roman; PATERNOTTE, David (org.). Anti-Gender Campaigns in Europe - Mobilizing against Equality. London: Rowman \& Littlefield Internacional Ltda, p. 253-276, 2017.

PENNA, Fernando. Escola sem Partido como chave de leitura do fenômeno educacional. In: FRIOGOTTO, Gaudêncio (org.). Escola "sem" partido: esfinge que ameaça a educação e a sociedade brasileira. Rio de Janeiro: UERJ, pp. 35-49, 2017.

ROSADO-NUNES, Maria J. F. A “ideologia de gênero" na discussão do PNE: a intervenção da hierarquia católica. Horizonte, Belo Horizonte, v. 13, n. 39, p. 1237-1260, jul./set. 2015. Disponível em:

http://periodicos.pucminas.br/index.php/horizonte/article/view/P.2175-5841.2015v13n39p123 7. Acesso em: 30 nov. 2019.

SCOTT, Joan. Gênero: uma categoria útil de análise histórica. Educação \& Realidade, v. 20, n. 2, p. 71-99, jul./dez. 1995. Disponível em:

https://seer.ufrgs.br/index.php/educacaoerealidade/article/view/71721. Acesso em: 30 nov. 2019.

SEFFNER, Fernando. Atravessamentos de gênero, sexualidade e educação: tempos difíceis e novas arenas políticas. Reunião Científica Regional da ANPED - Educação, movimentos sociais e políticas governamentais. UFPR - Curitiba, Paraná. Jul, pp. 1-17, 2016. Disponível em:

http://www.anpedsul2016.ufpr.br/portal/wp-content/uploads/2015/11/Eixo-18-G\%C3\%AAner o-Sexualidade-e-Educa\%C3\%A7\%C3\%A3o.pdf. Acesso em 30 nov. 2019. 
SILVA, Amanda da. Da "Ideologia de Gênero" à família heteronormativa: uma análise do Plano Municipal de Educação de Curitiba. Curitiba: UFPR, 2017, 136f., Dissertação (Mestrado em Educação), Universidade Federal do Paraná. Curitiba, 2017.

SILVA, Amanda da. CÉSAR, Maria Rita de A. A emergência da "ideologia de gênero" no discurso católico. InterMeio, Campo Grande (MS), v. 23, n. 46, p. 193-213, jul./dez. 2017. Disponível em: https://periodicos.ufms.br/ojs/index.php/intm/article/view/5318. Acesso em: 30 nov. 2019.

SILVA, Ivanderson Pereira da. Searching Meanings for the expression. "Gender Ideology". Educação em Revista, Belo Horizonte, v. 34, p. 1-29, 2018. Disponível em: http://www.scielo.br/pdf/edur/v34/en_1982-6621-edur-34-e190810.pdf. Acesso em: 30 nov. 2019.

TREINTA, Fernanda Tavares; FILHO, José Rodrigues Farias; SANT’ANNA, Annibal Parracho; RABELO, Lúcia Mathias. Metodologia de pesquisa bibliográfica com a utilização de método multicritério de apoio à decisão. Revista Production, v. 24, n. 3, p. 508-520, 2014. Disponível em:

http://www.scielo.br/scielo.php?script=sci_arttext\&pid=S0103-65132014000300002. Acesso em: 30 nov. 2019.

VAGGIONE, Juan M. La Iglesia Católica frente a la política sexual: la configurácion de una ciudadanía religiosa. Cadernos Pagu, n. 50, p. 1-35, 2017. Disponível em:

http://www.scielo.br/pdf/cpa/n50/1809-4449-cpa-18094449201700500002.pdf. Acesso em: 30 nov. 2019.

Recebido em setembro de 2020.

Aprovado em maio de 2021. 